\title{
High-Performance Liquid Chromatographic Determination of SAZ-VII-22, a Novel Antiarrhythmic Agent, in Dog Plasma and Urine
}

\author{
C. L. Chen*1, J. D. Roder*1, S. Sangiah*1†, H. Chen*1, K. D. Berlin*2, G. L. Garrison*2, \\ B. J. SCherLaG ${ }^{* 3, * 4}$, R. LAZZARA*3,*4 and E. Patterson $* 3, * 4$ \\ *1 Department of Physiological Sciences, College of Veterinary Medicine, Oklahoma State \\ University, Stillwater, OK 74078, USA \\ *2 Department of Chemistry, Oklahoma State University, Stillwater, OK 74078, USA \\ *3 Department of Medicine, OHSC, 921 N.E. 13th Street, Oklahoma City, OK 73104, USA \\ *4 The V.A. Medical Center, 921 N. E. 13th Street, Oklahoma City, OK 73104, USA
}

Keywords High-performance liquid chromtography, antiarrhythmic, pharmacokinetics, nonane

SAZ-VII-22 [3-(4-chlorobenzoyl)-7-isopropyl-3,7diazabicyclo[3.3.1] nonane, (A)](Fig. 1) has been shown to have effective antiarrhythmic properties with modest class-III antiarrhythmic activity. ${ }^{1,2}$ The basis of some electrophysiological effects of the antiarrhythmic properties of A could possibly be due to its inhibitory effects on myocardial $\mathrm{Na}^{+}, \mathrm{K}^{+}$-ATPase and $\mathrm{Mg}^{2+}$-ATPase activities. $^{3}$

There are no analytical methods currently available for determining the amount of $\mathbf{A}$ in biological fluids. This paper describes a rapid, selective HPLC technique for the determinaiton of this compound in biological fluids, including plasma and urine, which was successfully used to characterize preliminary pharmacokinetic profiles of $\mathbf{A}$ in a dog.

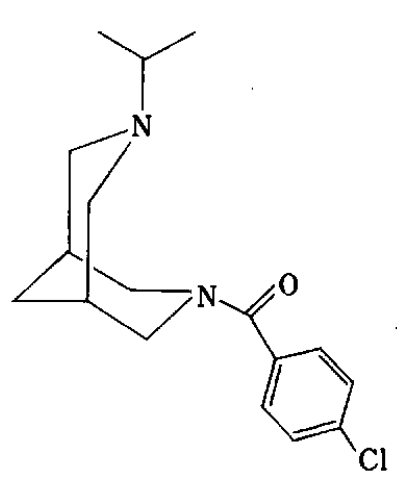

A

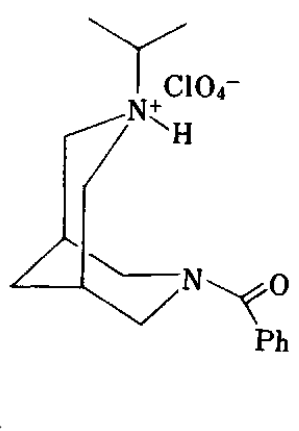

B
Fig. 1 Chemical structures of compounds $\mathbf{A}$ and $\mathbf{B}$. $\mathbf{A}$ is SAZ-VII-22; B is the internal standard.

\footnotetext{
$\dagger$ To whom correspondense should be addressed.
}

\section{Experimental}

\section{Chemicals}

All of the reagents used in this study were of HPLC grade; deionized water was used throughout a Milli-Q ${ }^{\text {TM }}$ Water System (Millipore Corp., Marborough, MA). Compound $\mathbf{A}$ and the internal standard, 3-benzoyl-7isopropyl-3,7-diazabicyclo[3.3.1] nonane $\cdot \mathrm{HClO}_{4}$ (B) (Fig. 1), were synthesized via a Mannich reaction starting from 4-thianone. ${ }^{4}$

\section{HPLC analysis}

The HPLC system comprised a Waters 501 HPLC pump, a Waters U6K universal liquid chromotography injector and a Model 484 Tunable Absorbance Detector controlled by a Baseline 810 Chromatography Work Station (Millipore, Milford, MA).

A $250 \times 4.6 \mathrm{~mm}$ Ultramex $5 \mathrm{C}_{6}$ column $(5 \mu \mathrm{m})$ and a $30 \times 4.6 \mathrm{~mm}$ Ultramex $5 \mathrm{C}_{6}$ column $(5 \mu \mathrm{m})$ (Phenomenex, Torrance, CA) were used as the analytical column and the guard column, respectively. The mobile phase was acetonitrile-methanol- $37.5 \mathrm{mM}$ phosphate buffer, pH $6.8(28.5: 28.5: 43 \mathrm{v} / \mathrm{v})$, containing $4 \mathrm{mM}$ triethylamine. The mobile phase was filtered through a $0.5 \mu \mathrm{m}$ Millipore filter and degassed before use. The column was eluted under isocratic conditions utilizing a flow rate of $1.2 \mathrm{ml} / \mathrm{min}$ at ambient temperature. The detection wavelength was $255 \mathrm{~nm}$.

\section{Extraction of $\boldsymbol{A}$ from dog plasma and urine}

To $250 \mu \mathrm{l}$ of dog plasma, $25 \mu \mathrm{l}$ of $20 \mu \mathrm{g} / \mathrm{ml}$ of the internal standard was added. Two milliliters of acetonitrile was added to precipitate any protein, and the supernatant was extracted with $3 \mathrm{ml}$ of chloroformpropanol $(9: 1)$. The organic phase was evaporated to 
dryness under a stream of $\mathrm{N}_{2}$. The residue was reconstituted in $50 \mu \mathrm{l}$ of methanol; $35 \mu \mathrm{l}$ of this solution was injected for an HPLC analysis. One half milliliters of urine samples were extracted directly with $5 \mathrm{ml}$ of chloroform after the samples were diluted with $4 \mathrm{ml}$ of water and alkalinized with $0.1 \mathrm{ml}$ of $5 \mathrm{M} \mathrm{NaOH}$.

\section{Drug administration and sampling}

Compound A, dissolved in DMSO (100\%), was administered intravenously to a healthy, adult, male mongrel dog at a dose of $10 \mathrm{mg} / \mathrm{kg}$. Blood samples $(c a .5 \mathrm{ml})$ were collected by vein puncture at various times. The plasma fractions were separated by centrifugation and stored at $-20^{\circ} \mathrm{C}$ until analysis. Urine was collected by a catheter and stored at $-20^{\circ} \mathrm{C}$ until being analyzed.

\section{Results and Discussion}

\section{Chromatographic separation}

Varying proportions of triethylamine in the mobile phase change both the retention time and the sharpness of the peak of compound $\mathbf{A}$. The $\mathrm{pH}$ of the mobile phase is a very important factor to control the retention time for A. Neither acetonitrile nor methanol alone was suitable as a strong solvent. It was determined that the combination described in the method was found to be the most suitable for separating $\mathbf{A}$ and $\mathbf{B}$. The retention times of $A$ and $B$ (internal standard) were $14.4 \pm 0.5$ and $10.7 \pm 0.3 \mathrm{~min}$, respectively.

\section{Extraction}

The use of acetonitrile to precipitate proteins offers great advantage, since using trichloroacetic acid (TCA) greatly decreased the absolute recovery. This may have been caused by the decomposition of compound $\mathbf{A}$. Dilution of the urine samples before extraction can reduce any accumulation of pollutants on the column. Extraction recoveries were $84 \%$ from the plasma and $96 \%$ from the urine, respectively.

\section{Calibration curves}

Calibration curves were generated by plotting peakarea ratios (drug/internal standard) against the drug concentrations tested. Each standard curve was replicated for five consecutive days. The standard curves obtained from the extraction of dog plasma and urine containing known amounts of $\mathbf{A}$ were linear $(r>0.998)$ over the concentration ranges tested. The range of the relative standard deviation (RSD) was lower than $9 \%$. The regression equations were $Y=-0.02990+$ $1.211 X$ for the plasma and $Y=-0.0119+0.559 X$ for the urine, respectively; here, $Y$ is the drug recovered in $\mu \mathrm{g} /$ $\mathrm{ml}$, and $X$ is the peak area ratio (drug/internal standard). The lower limit of the quantitation of $\mathbf{A}$ for both the plasma and urine was $0.04 \mu \mathrm{g} / \mathrm{ml}$, respectively.

\section{Intra- and inter-assay accuracy and precision}

The percentage of the mean concentration determined over the mean concentration added was taken as the accuracy of the method. The precision was estimated by determining the intra- and inter-assay RSD.

The obtained results indicate that the intra- and interassay RSD in the plasma and urine were less than $4 \%$. The accuracy of this method was $96-99 \%$.

\section{Applications to Dog Samples}

Representative HPLC profiles of the plasma sample of a dog given $A(10 \mathrm{mg} / \mathrm{kg})$ intravenously are shown in Fig. 2. The plasma concentration-time profiles of $\mathbf{A}$ in one dog given an intravenous dose of $10 \mathrm{mg} / \mathrm{kg}$ are shown in Fig. 3. The disposition of $\mathbf{A}$ in the plasma after intravenous administration was best described by a two-compartment model using a pharmacokinetic program. ${ }^{5}$ The half-life of the elimination was $55.8 \mathrm{~min}$; the half-life of the distribution was $5.7 \mathrm{~min}$; the area under the curve was $2.8 \mathrm{mg} / \mathrm{h} / \mathrm{l}$; the mean residence time was $2.5 \mathrm{~h}$; the apparent volume of distribution was $2.177 \mathrm{l} / \mathrm{kg}$; the median apparent volume of distribution was $4.733 \mathrm{l} / \mathrm{kg}$; the volume of the distribution at the steady state was $8.809 \mathrm{l} / \mathrm{kg}$; the total body clearance was $3.526 \mathrm{l}$ /

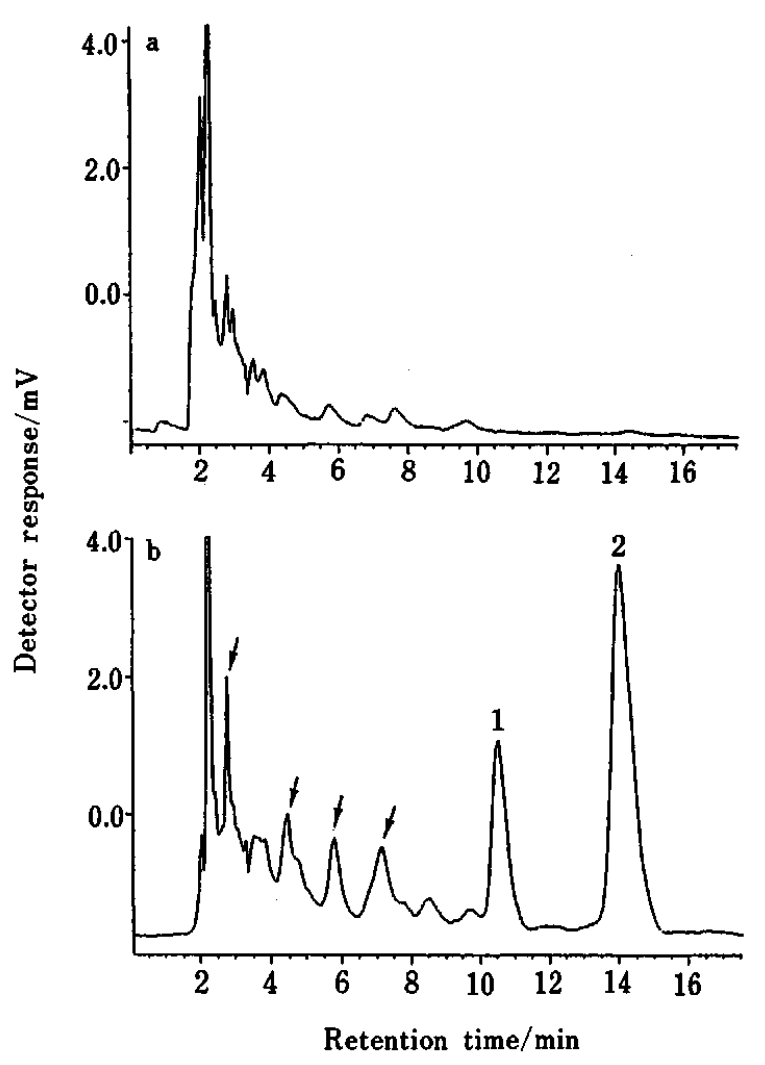

Fig. 2 HPLC profile of the blank plasma (a) and plasma sample $5 \mathrm{~min}$ after an i.v. dose of $10 \mathrm{mg} / \mathrm{kg}$ of $\mathbf{A}(\mathrm{b})$. See experimental for chromatographic conditions. Arrows show possible metabolites. Peaks. $1=\mathbf{B}$, internal standard, $2=\mathbf{A}$. The estimated concentration of $\mathbf{A}$ was $3.1 \mu \mathrm{g} / \mathrm{ml}$. 


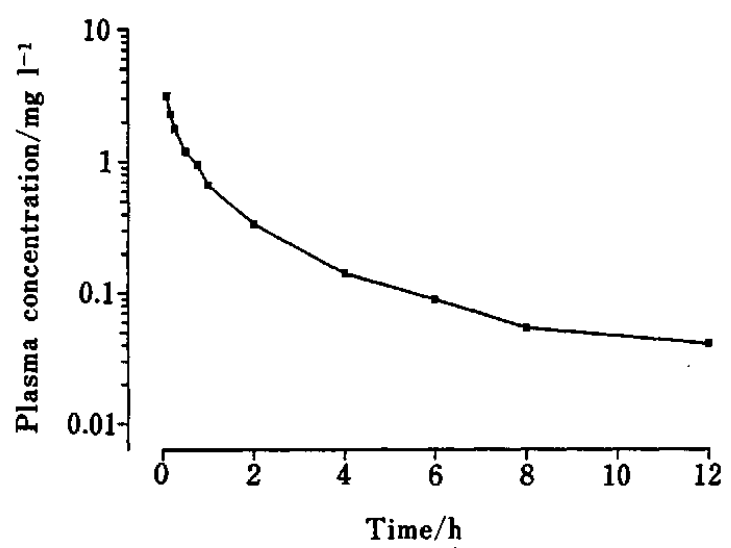

Fig.3 Plasma A concentration-time profiles after an i.v. dose of $10 \mathrm{mg} / \mathrm{kg}$ in one dog.

$\mathrm{h} / \mathrm{kg} ; k_{10}, k_{12}$ and $k_{21}$ were $1.823,3.220$ and $2.970 \mathrm{~h}^{-1}$, respectively; the hybrid rate constant $(\alpha)$ was $7.259 \mathrm{~h}^{-1}$, and $\beta$ was $0.7448 \mathrm{~h}^{-1}$; the zero-time plasma concentrations of $A$ and $B$ were 3.031 , and $1.565 \mathrm{mg} / 1$.

The results showed that the described HPLC method is suitable for pharmacokinetic studies of this novel antiarrhythmic agent.

This study was supported by an OCAST (Oklahoma Council of the Advancement for Science and Technology)/Presbyterian Applied Research Grant, the College of Art and Sciences, the College of Veterinary Medicine, Oklahoma State University, and the OSU Foundation.

\section{References}

1. S. A. Zisman, Ph. D. Dissertation, Oklahoma State University, 1989.

2. K. D. Berlin, unpublished data.

3. C. L. Chen, S. Sangiah, K. D. Berlin, G. L. Garrison, W. Dunn, Y. Nan, B. J. Scherlag, R. Lazzara and E. Patterson, Res. Commun. Chem. Pathol. Pharmacol., 78, 3 (1992).

4. S. T. Zisman, K. D. Berlin and B. J. Scherlag, Org. Prep. Proc. Intern., 22, 255 (1990).

5. D. W. A. Bourne, Computer Methods Programs Biomed., 29, 191 (1989).

(Received November 16, 1992) (Accepted April 27, 1993) 